\title{
A EVOLUÇÃO TECTONO-ESTRATIGRÁFICA DA PROVÍNCIA MINERAL DE CARAJÁS: UM MODELO COM BASE EM DADOS DE SENSORES REMOTOS ORBITAIS (SAR-C RADARSAT-1, TM LANDSAT-5), AEROGEOFÍSICA E DADOS DE CAMPO
}

\author{
PAULO VENEZIANI, ATHOS RIBEIRO DOS SANTOS \& WALDIR RENATO PARADELLA
}

\begin{abstract}
A TECTONICSTRATIGRAPHIC EVOLUTION OF THE CARAJÁS MINERAL PROVINCE: A MODEL BASED ON REMOTE SENSING (SAR-CRADARSAT-I, LANDSAT-5 TM), AERIAL GEOPHYSICS AND FIELD DATA Orbital remote sensing images have been used in Carajás Mineral Province (Brazilian Amazon Region) since the beginning of the 1990's. The Province, with a heterogeneous relief and almost totally covered by tropical rainforest, is part of the Itacaiúnas Shear Belt within the Amazonian Craton. The area is world-wide known due to its mineral potential. However, from the tectono-stratigraphic viewpoint it is still problematic due to several drawbacks such as poor access, physiographic complexity, and detailed information available only in few isolated sites (mining, deposits or mineralizations). Spaceborne optical (Landsat TM) and radar (C-HH RADARSAT-1) imageries and digital integrated products (RADARSAT-1/Aerialgammaspectrometry) have been extensively applied for geological mapping purposes in the Province. Due to their synoptic view coupled with distinct sensor/terrain geometry allowing the extraction of indirect geological information, these kinds of remotely sensed products have been interpreted based on specific morphostructural criteria., with the following objectives: (1) to integrate previous and disperse geological data; (2) to explore the identification of regional structures and distinct tectonic-stratigraphic regimes on a large mapping scale; (3) to distinguish different motion phases along the Itacaiúnas Shear Belt (WNW-ESE trending) and characterize related rock forming and deformation events. Fieldwork campaigns carried out along selected profiles have provided new information. These findings were integrated with previous data and have allowed the production of a new tectono-stratigraphic map for the Province (1:250,000 scale). In addition, it was also possible to characterize three ductile and brittle transpression phases, locally transtensive, with Archean/Neoproterozoic ages. It was also observed extensive reactivations with pulses at the end of the Proterozoic and beginning of the Palaeozoic, at the Mesozoic and at the Tertiary. Volcanism, sedimentation, granitogenesis, metamorphism and deformation with distinct intensity are associated with these phases. The records of these deformations are clear in orbital remote sensing images and can be used as diagnostic of the distinct motion/deformation events in the Province. These orbital images are fundamental tools for tectono-stratigraphic mapping purposes in the Province.
\end{abstract}

Keywords: tectono-stratigraphic evolution, Carajás Mineral Province, remote sensing, SAR

RESUMO Imagens de sensoriamento remoto orbital tem sido utilizadas na Província Mineral de Carajás (Amazônia brasileira) desde o início da década de 1990. A Província, com um relevo heterogêneo e quase totalmente coberta por floresta tropical, é parte do Cinturão Itacaiúnas, Craton Amazônico. A área é conhecida mundialmente por seu potencial mineral, porém do ponto de vista tectono-estratigráfico ainda apresenta informações insuficientes e por vezes conflitantes devido às suas características fisiográficas, de acesso e, por ser mapeada com detalhes somente nas áreas mineralizadas, nem sempre próximas entre si. Imagens orbitais ópticas (TM Landsat), de radar (C-HH RADARSAT-1) e produtos digitais integrados (RADARSAT-1/aerogamaespectrometria) têm sido extensivamente usados em mapeamento geológico na região. Devido às características sinópticas e geometria distinta de observação (sensor/terreno), permitindo derivar informações geológicas indiretas, estes tipos de produtos de sensores remotos tem sido interpretados através de critérios morfoestruturais específicos, com os seguintes objetivos: 1-integrar dados prévios e dispersos; 2- identificar estruturas regionais e diferentes ambientes tectono-estratigráficos de grande escala e; 3 - distinguir diferentes fases de movimentação ao longo do Cinturão Itacaiúnas, orientado em torno de WNW-ESE, e caracterizar eventos formadores e deformadores de rochas. Verificações de campo ao longo de perfis previamente selecionados forneceram dados elucidativos que, integrados aos preexistentes, permitiram a elaboração de um mapa tectono-estratigráfico na escala de 1:250.000. Além disso, foi também possível caracterizar três fases transpressivas dúcteis a rúpteis - dúcteis, localmente transtrativas, ocorridas no Arqueano/Paleoproterozóico e posteriores reativações distensivas com picos no final do Proterozóico/início do Paleozóico, no Mesozóico e no Terciário. A estas fases associaram-se vulcanismo, sedimentação, granitogênese e metamorfismo com diferentes graus de intensidade. Os registros destas deformações, sob as formas de arrastos dúcteis, deslocamentos e justaposição de unidades tectono-estratigráficas com idades diferentes, são evidentes nas imagens utilizadas e diagnósticos das diferentes fases de movimentação/deformação, o que permite considerá-las indispensáveis para a elaboração de sínteses tectono-estratigráficas regionais em ambientes similares aos da Província Mineral de Carajás.

Palavras-chave: evolução tectono-estratigráfica, Província Mineral de Carajás, sensoriamento remoto, radar imageador

INTRODUÇÃO A Província Mineral de Carajás é uma das mais importantes reservas minerais do Brasil, contendo os maiores depósitos de Fe do mundo, além de Au, $\mathrm{Cu}, \mathrm{Mn}, \mathrm{Ni}$ e Pt. Apesar de existirem vários trabalhos de cunho estratigráfico regional (p. ex.:
Hirata et al. 1982, Meireles et al. 1984, DOCEGEO 1988) e tectônico (p. ex.: Cordani \& Brito Neves 1982, Hasui \& Haraly 1985, Araújo et al. 1988, 1992, Siqueira \& Costa 1991, Macambira et al. 1994, Costa et al. 1994, Pinheiro 
1997) existem, ainda, problemas que dificultam o entendimento da geologia da região. Estes problemas, que se refletem diretamente na prospecção mineral, relacionam-se aos seguintes fatores, como enfatizou Pinheiro (1997):

1 - Mais de $80 \%$ da região possuem escassos e esparsos afloramentos, com o agravante de estarem cobertos pela densa floresta tropical;

2 - A intensa deformação destruiu o correlacionamento estratigráfico das rochas;

3 - Os mapeamentos de detalhe são baseados essencialmente nos aspectos litológicos localizados nas áreas mineralizadas (distantes entre si), resultando na criação de um conjunto de diferentes nomenclaturas estratigráficas.

O final da década de 80 e início dos anos 90 , marca um período de atividades de pesquisas na região, com a utilização intensiva de produtos de sensoriamento remoto óptico e de radar, integrados com dados aerogeofísicos. Embora as imagens de sensoriamento remoto já tenham sido empregadas anteriormente (p. ex.: Projeto RADAMBRASIL), avanços tecnológicos, tanto do ponto de vista dos sistemas sensores como dos processamentos digitais e dos métodos interpretativos (p. ex.: Santos et al. 1997, 2001, Paradella et al. 1998), incrementaram as possibilidades de obtenção de melhores e mais detalhadas informações geológicas. A continuidade dos estudos permitiu a aquisição de um volume considerável de dados que propiciou as condições necessárias para elaboração de um mapa tectono-estratigráfico e um modelo de evolução tectônica regional. A tabela 1 especifica as características dos dados de sensoriamento remoto utilizados para a interpretação geológica da região estudada.

Os dados aerogamaespectrométricos, cedidos pela Companhia de Pesquisa de Recursos Minerais - CPRM, fazem parte do Projeto Geofísico Brasil - Canadá (PGBC), realizado no período de 1975 1976. As linhas de vôo foram no sentido N-S, espaçadas de 1 km, com intervalo de amostragem equivalente a $65 \mathrm{~m}$ na superfície. $\mathrm{O}$ canal K não está disponível para a região analisada. Os dados foram previamente corrigidos e transformados em uma malha UTM, com uma resolução espacial de $125 \mathrm{~m}$. Os dados SAR (Synthetic Aperture Radar) e TM-Landsat foram ortorretificados com modelos digitais de elevação (DEMs) na escala de 1: $100.000 \mathrm{e}$ integrados aos dados gamaespectrométricos (Paradella et al. 1998).

LOCALIZAÇÃO DA ÁREA A área estudada situa-se entre os paralelos $05^{\circ} 25^{\prime} 35^{\prime \prime} \mathrm{e} 06^{\circ} 36^{\prime} 15^{\prime \prime}$ 'S e os meridianos $50^{\circ} 59^{\prime} 43^{\prime \prime}$ e 49 33' 04" W, no Estado do Pará. A figura 1 mostra a área de pesquisa localizada na imagem ScanSAR Narrow, com destaque para algumas das suas feições mais importantes.

CONTEXTO GEOLOGICO REGIONAL Os principais trabalhos de cunho regional que discorrem sobre a geologia da Província Mineral de Carajás são citados a seguir. Para melhor entendimento da nomenclatura utilizada, ver a Tabela 2. A figura 2 exibe o mapa simplificado da parte leste do Cinturão Itacaiúnas, com o intuito de melhor situar os aspectos da geologia regional que serão apresentados a seguir.

Cordani \& Brito Neves (1982) e Teixeira et al. (1989) caracterizaram a região da Província baseados em modelo de faixas móveis proterozóicas, ao redor de um craton arqueano. Os granulitos e migmatitos, que ocorrem ao norte da Serra de Carajás, seriam representantes do Cinturão Maroni-Itacaiúnas e os gnaisses e metavulcano-sedimentares, que constituem a estrutura dessa serra, foram correlacionados à Província Amazônia Central do Paleoproterozóico/Arqueano.

DOCEGEO (1988) subdivide a província em três unidades:

a) Complexo Xingu, com gnaisses tonalíticos e granodioríticos e rochas metassupracrustais;

b) Supergrupo Itacaiúnas, englobando todas as rochas metavulcano-sedimentares (grupos Igarapé Salobo, Igarapé Pojuca e Grão-Pará) e "metarenitos"(Grupo Rio Fresco-Formação Águas Claras, de Araújo \& Maia 1991) e;

c) Granitos intrusivos proterozóicos.

Araújo \& Maia (1991) e Oliveira et al. (1994) consideraram a região como parte do Cinturão de Cisalhamento Itacaiúnas e distinguiram três domínios regionais;

a) Meridional, caracterizado por zonas de cisalhamento imbricadas que deformaram as rochas dos complexos Xingu e Pium, da Suite Plaquê e do Grupo Sapucaia;

b) Central, afetado por transcorrências dos sistemas Carajás (flor positiva), Cinzento, Tapirapé e Buritirama e;

c) Setentrional, onde rochas granulíticas encontram-se tectonicamente imbricadas com rochas do Complexo Xingu e, subordinadamente, com rochas metassedimentares.

Com suporte em datações geocronológicas, os autores citados consideraram toda a sequiência de idade arqueana, com exceção dos granitos anorogênicos (Neoproterozóico a Paleoproterozóico) e coberturas sedimentares da Serra do Paredão e respectivas intrusivas básicas.

Pinheiro (1997) e Pinheiro \& Holdsworth (2000) com base nas "relações geológicas das unidades, com as principais fases de movimentos dúcteis ao longo da Zona de Cisalhamento Itacaiúnas", subdividiram tectono - estratigraficamente as regiões dos sistemas de cisalhamento Carajás (domínio da serra) e Cinzento (a norte), da seguinte maneira:

a) Assembléia embasamental, composta por ortognaisses e plutons granitóides (Complexo Xingu) e por seqüências metavulcano-sedimentares, quartzitos, xistos, anfibolitos e

Tabela 1 - Principais características dos dados de sensoriamento remoto utilizados na pesquisa.

\begin{tabular}{|c|c|c|c|c|c|c|c|}
\hline Satćlite & $\begin{array}{l}\text { Sensort } \\
\text { Imagem }\end{array}$ & $\begin{array}{l}\text { Bandal } \\
\text { Posição* }\end{array}$ & Escala & Data & $\begin{array}{c}\text { Resolução } \\
\text { Espacial } \\
(\mathrm{m}) \\
\end{array}$ & $\begin{array}{l}\text { Elev. Solart } \\
\text { Incidênciat }\end{array}$ & $\begin{array}{c}\text { Az. Solarl } \\
\text { Az. de } \\
\text { lluminação }\end{array}$ \\
\hline \multirow{2}{*}{ L.andsat-5 } & \multirow{2}{*}{$\begin{array}{c}\text { TM } \\
\text { WRS } 226 / 064\end{array}$} & 4 & !: 250.000 & $22 / 06 / 86$ & 30 & $43^{\circ}$ & $50^{\circ}$ \\
\hline & & 5 & I: 250.000 & $22 / 06 / 86$ & 30 & $43^{\circ}$ & $50^{\circ}$ \\
\hline \multirow{5}{*}{ RADARSAT - 1} & \multirow{4}{*}{$\begin{array}{l}\text { SAR-C } \\
\text { Standard }\end{array}$} & S5I) & $1: 250.000$ & $31 / 05 / 96$ & $24,2 \times 27$ & $36 / 42^{\circ}$ & $282^{\circ}$ \\
\hline & & S5A & 1: 250.000 & $28 / 08 / 97$ & $24,2 \times 27$ & $36 / 42^{\prime \prime}$ & $78^{\circ}$ \\
\hline & & $S 6 A$ & 1: 250.000 & $28 / 11 / 96$ & $22,1 \times 27$ & $41 / 46^{\circ}$ & $78^{\circ}$ \\
\hline & & S7D & 1:250.000 & $11 / 09 / 96$ & $22,09 \times 27$ & $45 / 48^{\circ}$ & $282^{\circ}$ \\
\hline & $\begin{array}{c}\text { SAR-C } \\
\text { ScanSAR Narrow }\end{array}$ & $\mathrm{SN} 2 \mathrm{D}$ & $1: 250.000$ & $15 / 11 / 96$ & $55.1 \times 71.7$ & $31 / 46^{\circ}$ & $282^{\circ}$ \\
\hline
\end{tabular}




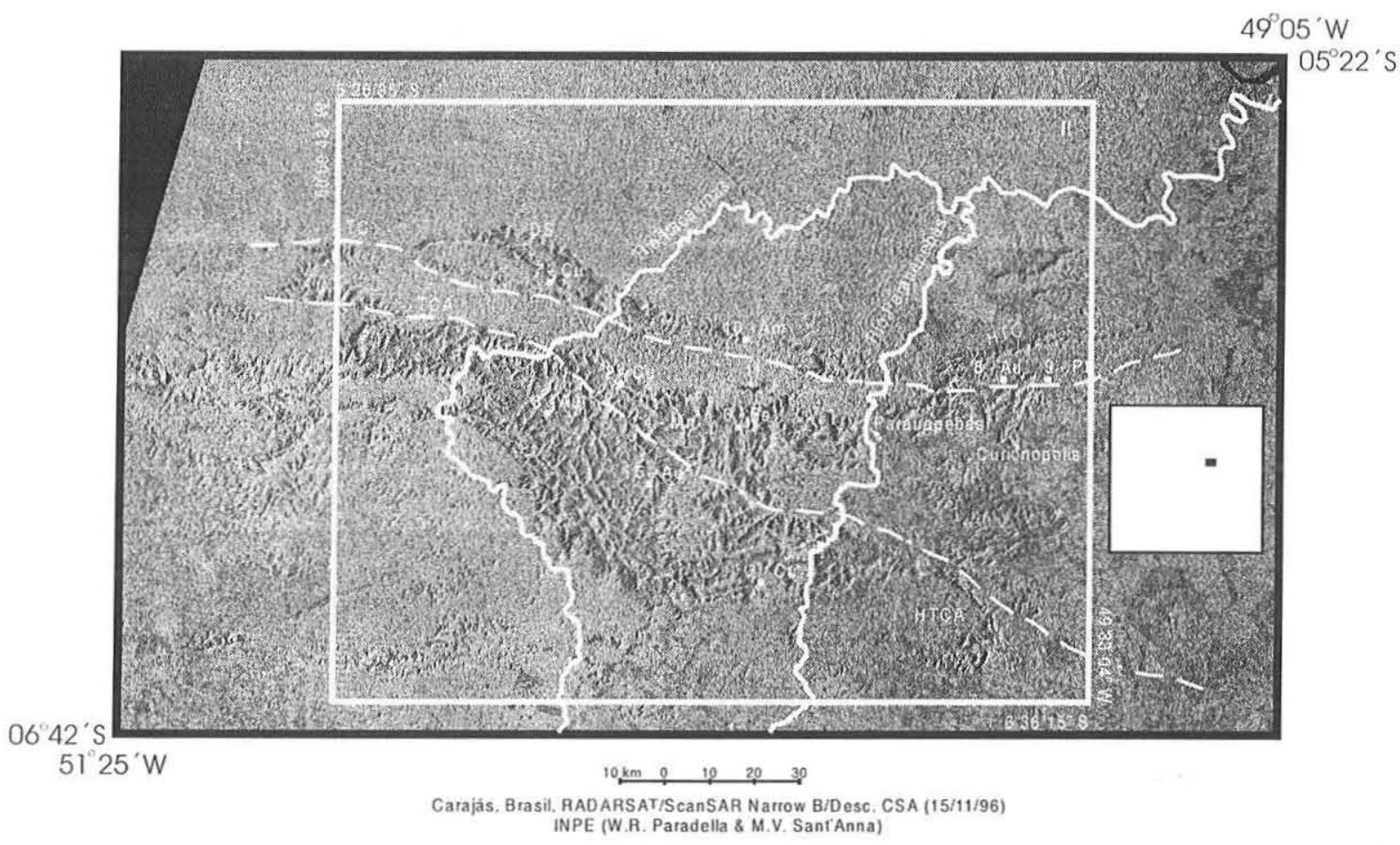

Figura I - Imagem ScanSAR Narrow e localização da área de estudo. I - imagem ScanSAR Narrow; II - área comum das imagens TM-Landsat-5 e RADARSAT-I Standard; TC - traço principal da Zona de Cisalhamento Transcorrente (ZCT) do Cinzento; TCA - traço principal da ZCT Carajás; DS - Duplex Salobo; HTC - Horse Tail Splay de Carajás; I - Jazida de Salobo; 2 - Jazida do Pojuca; 3 - Jazida do Bahia; 4 - Jazida do Azul; 5 - Jazida Águas Claras; 6 - Jazida N4; 7 - Jazida do Sossego; 8 - Jazida Serra Pelada; 9 - Jazida do Luanga; 10 - Jazida Ametista; II - Lagos Gelado e Geladinho.

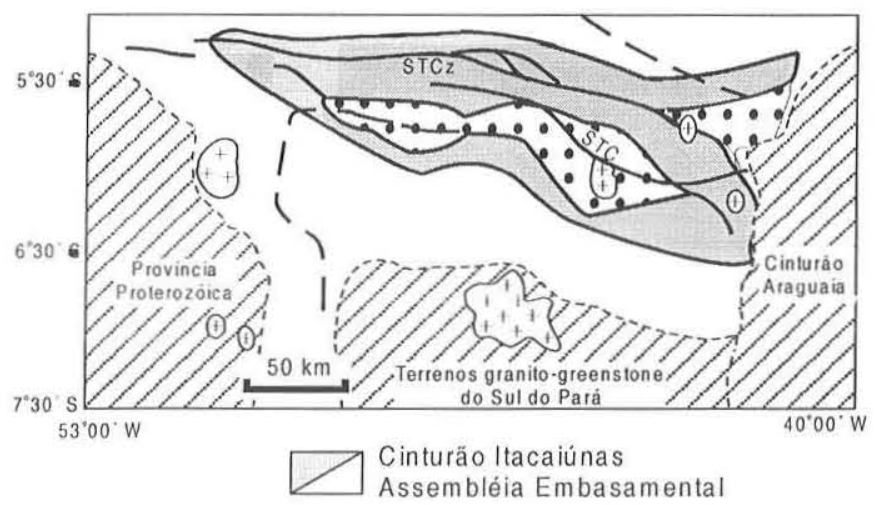

-. Assembléia de Cobertura $+t_{+}^{+}+{ }_{+}^{+}$Granitos Proterozóicos

Figura 2 - Mapa simplificado da parte leste do Cinturão Itacaiúnas. STCz-Sistema Transcorrente do Cinzento; STCSistema Transcorrente Carajás (Fonte: Modificado de Pinheiro \& Holdsworth 2000).

formaçōes ferríferas (Grupo Igarapé Salobo). Tais rochas mostramse intensamente deformadas (cisalhamento dúctil) e metamorfizadas em alto grau, de forma a obliterar a reconstituição estratigráfica das diferentes unidades geológicas;

b) Assembléia de cobertura, composta por rochas vulcanosedimentares de baixo grau metamórfico, também deformadas pelos movimentos ao longo do Cinturão de Cisalhamento Itacaiúnas (grupos Igarapé Pojuca e Grão-Pará), recobertas por depósitos clásticos (Formação Águas Claras).

As assembléias de cobertura e embasamental foram intrudidas por plutons graníticos e diques básicos de diferentes gerações e apresentam, localmente, coberturas conglomeráticas (Formação Gorotire?,Pinheiro 1997).

Com relação à evolução tectono-estratigráfica, foram publicados importantes modelos de cunho regional. Os mais abrangentes são os de Araújo \& Maia (1991), Oliveira et al. (1994), Costa et al. (1995), Pinheiro (1997) e Pinheiro \& Holdsworth (2000). Embora existam algumas divergências entre esses autores, as propostas são bastante semelhantes. De um modo geral, os principais pontos convergentes são:

a) A região está inserida no Cinturão de Cisalhamento Itacaiúnas, orientado segundo WNW-ESE;

b) Um cisalhamento, de natureza dúctil, afetou as rochas infracrustais (complexos Pium e Xingu e a Suite Monte Bacajaí) e parte das coberturas representadas pelo Supergrupo Itacaiúnas. Este evento está associado a um conjunto de movimentos sinistrais oblíquos (empurrões imbricados), relacionados às transcorrências regionais;

c) $\mathrm{O}$ desenvolvimento desta movimentação ocorreu no Arqueano;

d) Foi reconhecido um episódio de natureza destral transtensivo (ao longo de WNW-ESE), também arqueano, que deu origem a uma série de bacias e;

e) A partir do Neoproterozóico (1,9 - 1,8 Ga, Pinheiro \& 
Holdsworth 2000), passaram a predominar movimentos distensivos, responsabilizados pela alocação dos granitos anorogênicos e de intrusões básicas, principalmente sob a forma de diques.

Pinheiro \& Holdsworth (2000) sugeriram para os sistemas transcorrentes Carajás e Cinzento, durante o intervalo entre 2,8 e 1,9 Ga, os seguintes eventos: transpressivo sinistral $(2,8 \mathrm{Ga})$; extensivo (intracratônico, 2,7 Ga); transtracional destral (2,6 Ga); transpressivo sinistral/transtensivo (1,9 Ga). A partir deste último reconheceram reativações extensivas, até a atualidade. Tais eventos estão diretamente correlacionados com os fenômenos de formação de rochas, metamorfismo - deformação, embaciamento, sedimentação, vulcanismo e granitogênese da região.

Santos et al. (2001), Veneziani \& Okida (2001) e Veneziani et al. (2001), utilizando produtos de sensores remotos e dados, tanto bibliográficos quanto de campo, definiram para a região as seguintes fases de movimentação/deformação ao longo do Cinturão Itacaiúnas:

1 - Transpressiva sinistral com direção principal orientada segundo WNW-ESE, vergência de NE para SW e o desenvolvimento de zonas de cisalhamento de natureza dúctil. $\mathrm{O}$ cisalhamento progressivo não coaxial afetou as rochas embasamentais, os granitóides da Suite Plaquê e as rochas dos grupos Sapucaia, Igarapé Pojuca e Igarapé Salobo (Tabela 2);

2 -Transpressiva oblíqua, localmente transtrativa, com direção principal orientada em torno de WNW-ESE e vergência de NNW para SSE. Desenvolveram-se zonas de cisalhamento dúcteis a rúpteis - dúcteis, com inversão de movimentos em relação à primeira fase, ao longo das antigas linhas de fraquezas crustais. $\mathrm{O}$ cisalhamento progressivo não coaxial criou condições favoráveis à ocorrência de extensão (zonas transtrativas), deposição e extrusão de rochas vulcânicas, desde ultramáficas a intermediárias (Grupo Rio Novo, Complexo Luanga e Grupo Grão-Pará), bem como granitogênese sintectônica (granitos do tipo Estrela). Com a continuidade dos movimentos, tais rochas foram deformadas sob regimes dúctil a rúptil. Ainda durante esta fase, podem ter ocorrido as condições necessárias de extensão e adelgaçamento crustal para a formação da bacia do Águas Claras (Tabela 2);

3 - Transpressiva rúptil, localmente transtensiva, sinistral, com a direção principal orientada em torno de N70W e vergência de NE para SW. Ocorreu o desenvolvimento/reativação das antigas linhas

Tabela 2 - Principais características das unidades tectono-estratigráficas da Província Mineral de Carajás.

\begin{tabular}{|c|c|c|c|}
\hline II)A DE: & I VIDADESTECTONO- ESTRATIGRÁFICAS & WETAMORFISMO & DEFORIIACYIO \\
\hline$?$ & Rochas intrusivals básicas: diabásio (Oliveira $e$ al. & nĩo metamórfico & rúptil \\
\hline $\begin{array}{l}\text { Siluro-ordoviciano } \\
\text { (?) }\end{array}$ & $\begin{array}{l}\text { Grupo Serra do Paredão: ortoquartzitos e } \\
\text { conglomerados polimícticos (Figueirat et al. 1987) } \\
\text { Grupo Serra Grande (Pinheiro 1997. Pinheiro \& } \\
\text { Holdsworth 2000) }\end{array}$ & não metamórfico & rúptil \\
\hline Neoproterozóico & $\begin{array}{l}\text { Formaçao Gorotire: arcósios, arenitos e conglomerados } \\
\text { polimícticos (Hirata et al. 1982, Pinheiro } 1997 . \\
\text { Pinheiro \& Holdsworth 2000) }\end{array}$ & não metamórfico & rúptil \\
\hline \multirow[t]{2}{*}{$\begin{array}{l}\text { Neoproterozóico } \\
\text { a } \\
\text { Paleoproterozóico }\end{array}$} & $\begin{array}{l}\text { Granitos A norogênicos (Dall'A gnol el al. } 1986 . \\
\text { Macambira el al. 1992, Pinheiro 1997, Pinheiro \& } \\
\text { Holdsworth 2000) }\end{array}$ & não metamórfico & rúptil \\
\hline & $\begin{array}{l}\text { Grupo Buritirama: quartzitos e argilitos (DOCEGEO } \\
\text { 1988) }\end{array}$ & $\begin{array}{l}\text { Fracamente } \\
\text { metamórfico }\end{array}$ & rúptil \\
\hline $\begin{array}{l}\text { Palcoproterozóico } \\
\text { a Arqueano } \\
(1,88 \text { a } 2,6 \text { Gai })\end{array}$ & $\begin{array}{l}\text { Formação Águas Claras: pelitos, siltitos e arenitos } \\
\text { (A raújo et al. 1988, Nogueiral 1995. Pinheiro \& } \\
\text { Holdsworth 2000) }\end{array}$ & não metamórfico & rúptil \\
\hline \multirow[t]{4}{*}{$\begin{array}{l}\text { Arqueano } \\
(2.76 \text { a } 2.65 \text { Ga })\end{array}$} & $\begin{array}{l}\text { Complexo Granítico Estrela: granitos sintectônicos com } \\
\text { diferentes composições (Barros \& Dall' A gnol 1994) }\end{array}$ & xisto-verde baixo & dúctil-rúptil \\
\hline & 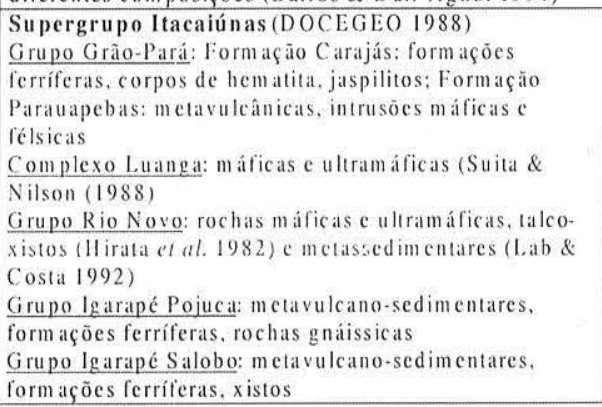 & $\begin{array}{l}\text { xisto-verde baixo } \\
\text { xisto-verde baixo } \\
\text { xisto-verde baixo } \\
\text { xisto-verde baixo } \\
\text { xisto-verde }\end{array}$ & $\begin{array}{l}\text { dúctil-rúptil } \\
\text { dúctil } \\
\text { dúctil } \\
\text { dúctil } \\
\text { dúctil }\end{array}$ \\
\hline & $\begin{array}{l}\text { Grupo Sapucaia: metavulcano-sedimentares (A raújo \& } \\
\text { Maia 1991) }\end{array}$ & xisto-verde & dúctil \\
\hline & $\begin{array}{l}\text { Suite Plaquê: granitos sintectónicos (A raújo et al. } 1988 \text {, } \\
\text { Araújo \& Maia 1991) }\end{array}$ & $\begin{array}{l}\text { anfibolito a } \\
\text { granulito }\end{array}$ & dúctil \\
\hline $\begin{array}{l}\text { Arqueano } \\
(>2.8(\text {; } i)\end{array}$ & $\begin{array}{l}\text { Complexo Granítico - Gnáissico (Silva et al. } 1974, \\
\text { DOCE(GEO 1988. A raújo et al. } 1988 \text {. A raújo \& Maia } \\
1991 \text {, Oliveira et al. 1994) } \\
\text { Complexo Xingu Indiferenciado: gnaisses tonalíticos, } \\
\text { trondhjem itos, granitos, granodioritos e anfibolitos. } \\
\text { Neste trabalho: X Xingu A: paragnaisses e granitóides: } \\
\text { Xingu B: gnaisses, metabásicas e xistos máficos; Xingu } \\
\text { C: granodioritos, tonalitos e gnaisses } \\
\text { Complexo Pium e Suite Monte Bacajaí: granulitos, } \\
\text { charnockitos, enderbitos e kinzigitos }\end{array}$ & $\begin{array}{l}\text { anfibolito a } \\
\text { granulito }\end{array}$ & dúctil \\
\hline
\end{tabular}


de fraquezas crustais sob a forma de falhas transcorrentes, cujos principais exemplos são os sistemas de falhas de Carajás e Cinzento. Foram criadas as condições favoráveis, nos locais onde predominou a transtração, para a intrusão de plutons graníticos (p. ex.: Granito Central, granitos anorogênicos) e diques, bem como para a formação da bacia do Buritirama (Tabela 2);

4-Reativação generalizada com movimentação principalmente na vertical e, secundariamente, lateral (destral) que afetou, inclusive, as regiões de contato dos granitos anorogênicos, e propiciou a formação da bacia do Gorotire (Tabela 2);

4 - A partir do Neoproterozóico predominou a cinemática extensional, responsável por reativações das antigas linhas de fraquezas crustais. Tais reativações estão registradas nas ocorrências de sedimentos paleozóicos (Grupo Serra Grande), intrusivas básicas mesozóicas e coberturas terciárias (Tabela 2).

ANÁLISE CINEMÁTICA As características petrográficas e metamórficas da área (Tabela 2) indicam a ocorrência de rochas formadas e/ou deformadas em ambientes, desde os de grande profundidade e altas temperaturas, até aqueles pouco profundos e não metamórficos. Portanto, as deformações variam desde dúcteis até rúpteis. Estas características são comuns em terrenos policíclicos e polimetamórficos que sofreram deslocamento e deformação progressiva, pois é comum na região estudada observar estruturas que foram desenvolvidas em um estágio inicial da seqüência deformacional e tiveram a sua geometria modificada em estágios finais ou foram superpostas por novas estruturas.

Na escala de afloramentos, várias feições indicativas de cisalhamento dúctil podem ser identificadas, como por exemplo, foliação milonítica, estruturas S-C, bandas de cisalhamento, dobras intrafoliais, dobras de interferência entre diferentes zonas de cisalhamento (estruturas St), arrastos dúcteis, rotações, off set de estruturas, splays, lineações de estiramento, boudinage, assimetria de porfiroclastos, etc. Da mesma forma, podem ser observadas feições de natureza dúctil-rúptil a rúptil-dúctil quando, e dependendo da intensidade de fraturamento, verifica-se a combinação das feições descritas com estruturas frágeis (falhas). Quando estas predominam, feições como estrias, marcas de arrancadura, rompimento de corpos, etc. indicam a natureza rúptil das deformações. Em relação à cinemática, vários indicadores em afloramentos mostram o sentido dos movimentos, se o cisalhamento foi puro ou simples e se a deformação foi progressiva.

Em megaescala, isto é, com produtos de sensoriamento remoto utilizados, é possível analisar os grandes processos de evolução crustal mediante os tipos de deformação devidos aos cisalhamentos simples e puro. Os critérios baseiam-se no estabelecimento da correlação entre as feições morfoestruturais regionais e os modelos deformacionais teórico-empíricos consagrados (Santos et al. 2001). Como resultados desta correlação, podem ser feitas previsões que indicam as possíveis estruturas que serão encontradas em afloramentos.

Realizou-se uma integração inicial com os mapeamentos regionais prévios (DOCEGEO 1988, Araújo \& Maia 1991, Oliveira et al. 1994, Pinheiro 1997) e com os produtos integrados de sensores remotos e gamaespectrométricos (Paradella et al. 1997). A figura 3 exemplifica um produto integrado RADARSAT-1 S7D \& Gama Contagem Total da Folha Serra dos Carajás (1: 100.000), utilizado na interpretação geológica. Obteve-se um mapa tectono-estratigráfico na escala de 1: 250.000, reduzido neste trabalho (Fig. 13), com as unidades diferenciadas em função da intensidade/complexidade deformacional.
A morfologia da distribuição espacial das estruturas regionais (Fig. 1) foi, inicialmente, comparada com o esquema de Biddle \& Christie-Blick (1985) de zonas de cisalhamento transcorrente (Fig. 4). As feições esquematizadas foram prontamente reconhecidas sobre a imagem RADARSAT-1 ScanSAR Narrow (Fig. 1). Como exemplos citam-se: 1 - Duplex do Salobo (DS), que faz parte do Sistema Transcorrente Cinzento (TC);2 - Sistema Transcorrente Carajás (TCA); 3 - Terminais em "rabo de cavalo" (horse tails) dos sistemas Carajás (HTC) e Cinzento (TC) e várias outras estruturas que serão descritas posteriormente.

Nas imagens RADARSAT-1 Standard e banda 4 do TM-Landsat5 , com resoluções espaciais melhores que a do RADARSAT-1 ScanSAR Narrow (Tabela 1), foram analisadas feições menores (de drenagem e relevo) que forneceram evidências de movimentos tectônicos ao longo das zonas de cisalhamento regionais (Veneziani 1987, Santos et al. 2001). O arranjo espacial destas feições é semelhante a reflexos em megaescala dos indicadores cinemáticos observados nos afloramentos. Um dos exemplos mais marcantes é o da morfoestrutura da Serra dos Carajás (Fig. 1): o sigmóide é resultante da rotação induzida durante as fases distintas de movimentações destrais obliquas (dúcteis - rúpteis) e sinistrais (rúpteis - dúcteis), ao longo da direção WNW-ESE.

Para cada segmento de uma zona de cisalhamento transcorrente (ZCT, Fig. 4) existem estruturas peculiares. Ao observar-se a figura 1 identifica-se trechos retilíneos e encurvados. Estes últimos (bends), podem ter origem transpressiva (restraining bends) ou transtensiva (releasing bends). Nestes segmentos se desenvolvem também sistemas transcorrentes oblíquos, de

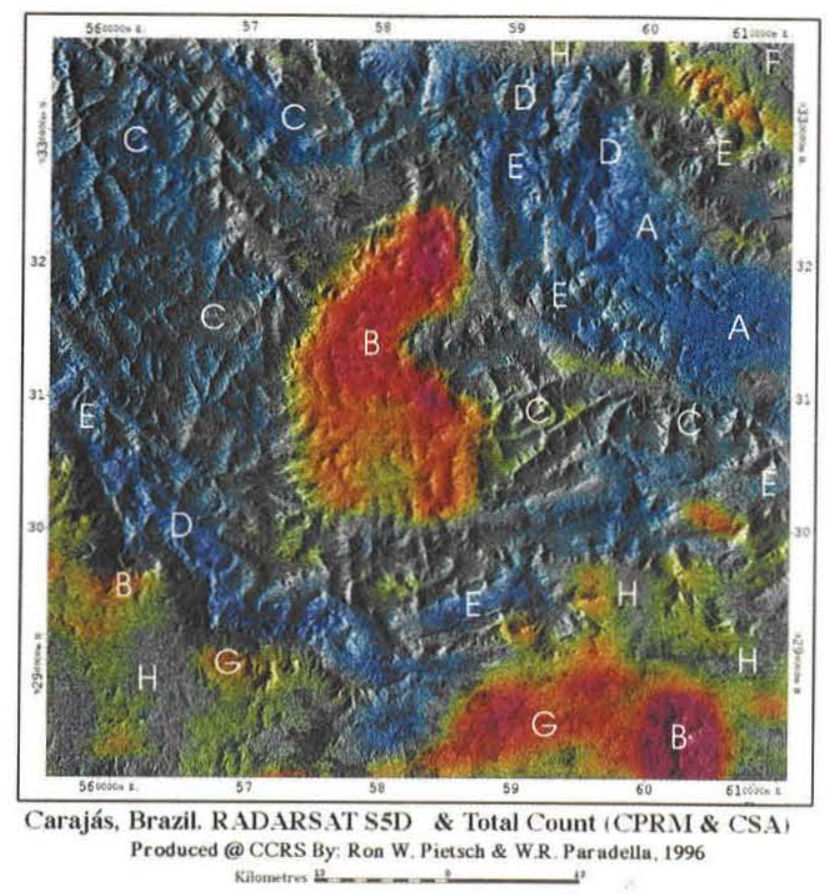

Figura 3 - Produto integrado RADARSAT-I S7D \& Gama Contagem Total (Folha Serra dos Carajás). Legenda: A Formação Gorotire; B - Granitos anorogênicos; $C$-Formação Águas Claras; Grupo Grão Pará: D - Formação Carajás e EFormação Parauapebas; F-Grupo Igarapé Pojuca; $G$ - Suite Plaquê; $H$ - Complexo Xingu Indiferenciado. Obs.: os limites das unidades podem ser observados na figura 13. 

RADARSAT-1, TM LANDSAT-5), aerogeofisica e dados de campo

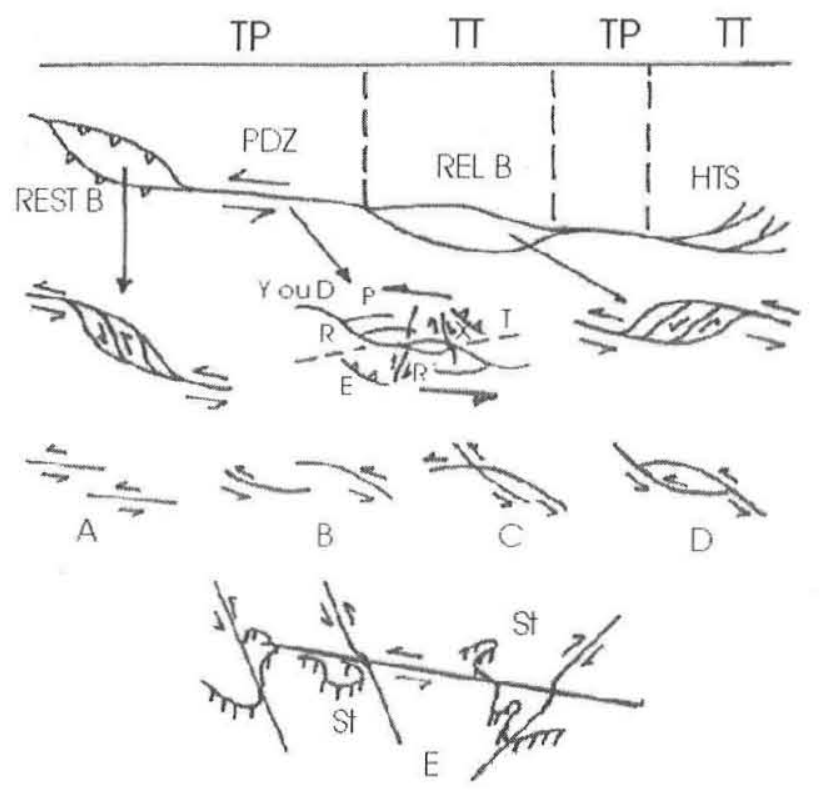

Figura 4 - Principais estruturas desenvolvidas ao longo de uma zona ou cinturão de cisalhamento transcorrente: TP-predomínio de estruturas transpressivas; TT - predomínio de estruturas transtrativas; PDZ - zona principal de deslocamento; HTS horse tail splay; REL. B-releasing bend; REST. B - restraining bend; $Y$ ou $D$ - direção principal; $R$ e $P$-sintéticas; $R$ ' $e X-$ antitéticas; $E$ - empurrões/inversas; $T$ - trativas (Fonte: modificado de Biddle \& Christie-Blick 1985). Propagação de zonas de cisalhamento: (a) aproximação de zonas de cisalhamento transcorrente ( ZCTs) planares; (b) encurvamento; (c) intersecção e (d) anastomosada (Fonte: Ramsay 1980). (e) Exemplos de dobras geradas pelo cisalhamento (St) e figuras de interferência encontradas na área.

empurrões/inversos e falhas normais, que correspondem às estruturas secundárias da zona de cisalhamento. Nos terminais das ZCTs desenvolvem-se horse tails (Figs. 1 e 4). Ao longo destes, podem ocorrer movimentos oblíquos com componente vertical de alto ângulo, caracterizando zonas transtensivas.

Nos níveis crustais superiores predominam estruturas rúpteis, que correspondem às fraturas Riedel ( $\left.R, \mathrm{R}^{\prime} \mathrm{e} \mathrm{P}\right)$. A zona principal corresponde a Y ou D (Fig. 4). Observam-se ainda as falhas X (antitéticas), T (trativas) e empurrões/inversas. Os duplexes desse nível podem ser divergentes ou convergentes. No primeiro caso, caracterizam-se rombho grabens/rombho chasms ou as estruturas de ejeção, correspondentes, respectivamente, aos releasing bends e restraining bends dos níveis crustais dúcteis - rúpteis (Harding 1974, Biddle \& Christie-Blick 1985).

As diferentes estruturas formadas ao longo das ZCTs estão presentes na região estudada. São devidas não somente a uma fase de movimentação, mas a fases distintas bem demarcadas no tempo. Alguns dos exemplos mais marcantes são observados na imagem ScanSAR Narrow (Fig. 1): os horse tails dos sistemas Cinzento e Carajás. Tais sistemas orientam-se subparalelamente a WNW-ESE. O primeiro terminal (Cinzento) inflete-se para NE eo segundo (Carajás) para SE. Tal fenômeno não ocorreria se duas fases distintas de movimentação, sinistral e destral respectivamente, não tivessem se desenvolvido segundo WNW-ESE.

A análise morfoestrutural, a comparação dos resultados desta com os modelos evolutivos preexistentes e a integração com os dados de campo descritos por vários autores e entidades (p. ex.: Pinheiro 1997, CPRM, CVRD, etc.) e aqueles obtidos em perfis previamente selecionados pelos autores do presente trabalho (cerca de 400 pontos, no total), permitiram definir as fases de movimentação/deformação ocorridas na área.

RESULTADOS Eventos evolutivos no intervalo de 2,8a 1,88 Ga As figuras 5,8 e 13 esquematizam os resultados obtidos. Os lineamentos representam antigas linhas de fraquezas crustais ao longo das quais desenvolveram-se movimentos diferenciados, durante diferentes períodos. As unidades tectono-estratigráficas delimitadas são aquelas deformadas em cada fase de movimentação.

PRIMEIRA FASE O conjunto litológico que compõe o Complexo Granítico - Gnáissico é ainda muito pouco conhecido. Envolve rochas metamórficas de fácies anfibolito a granulito (Tabela 2) intensamente deformadas, de forma dúctil, que se inserem na série milonítica. Constituem o pacote de infracrustais que, em conjunto com os granitóides da Suite Plaquê, as coberturas metavulcanosedimentares dos grupos Sapucaia, Igarapé Salobo e Igarapé Pojuca, foram afetados por movimentos transcorrentes sinistrais. A direção principal do cisalhamento (Fig. 5, Y ou D) orientava-se em torno de N85W durante esta fase. Portanto, o esforço principal $(\sigma \mathrm{l})$ regional posicionava-se em torno de $50^{\circ}$ a $65^{\circ}$ de acordo com os modelos teórico-empíricos.

Os condicionadores tectono/estruturais do embaciamento, do vulcanismo e da sedimentação dos grupos citados são incertos pela falta de exposição de contatos entre as unidades que os definem e as infracrustais. Algumas hipóteses podem ser aventadas. Observando-se os esquemas das figuras 4 e 5 , destacam se as seguintes evidências: 1 - a região do Duplex do Salobo, no início da fase em questão, pode ter se comportado como uma zona divergente transtracional; 2 - a nor-nordeste da região onde atualmente localiza-se o Granito Estrela (Figs. 9 e 13) pode ter ocorrido transtensão, devido às características de horse tail/splay divergente e; 3 - a sudeste do referido granito deve ter ocorrido tração, do tipo horst/graben, condicionada pelas estruturas subparalelas à direção tracional $\mathrm{T}$.

Com a continuidade da movimentação, as unidades em questão foram então deformadas, fato este que é demonstrado pelas evidências de transcorrência sinistral, atestada pelas ocorrências de zonas de cisalhamento dúctil orientadas em torno de EW e de shear folds. A vergência desta fase foi de NE para SW $(\sigma 1 \mathrm{em}$ torno de $50^{\circ}$ a $65^{\circ}$ e seus registros, embora escassos devido à superposição e intensa transposição causadas pelas deformações das fases seguintes, são verificados em núcleos preservados, como as partes centrais das lentes de cisalhamento (amêndoas).

Em escala de afloramentos a vergência mencionada foi atestada por autores, tais como, Araújo \& Maia (1991), Pinheiro \& Holdsworth (2000), entre outros, e pela equipe do presente trabalho em campanhas de campo. Destacam-se vários afloramentos ao longo do Rio Itacaiúnas, a partir da Serra dos Carajás rumo nordeste; nas regiões dos lagos Gelado e Geladinho; no município de Curionópolis e na região da Mina do Sossego (Fig. 1). Dentre esses, escolheram-se dois exemplos (Figs. 6e 7), que representam, tipicamente, indicadores cinemáticos, de natureza dúctil, gerados por cisalhamento simples.

A relação espacial entre as direções orientadas em torno de WNW-ESE (Y ou D) e de N60E (T), principalmente no corpo da estrutura de Carajás (sigmóide), nos arredores do Complexo 


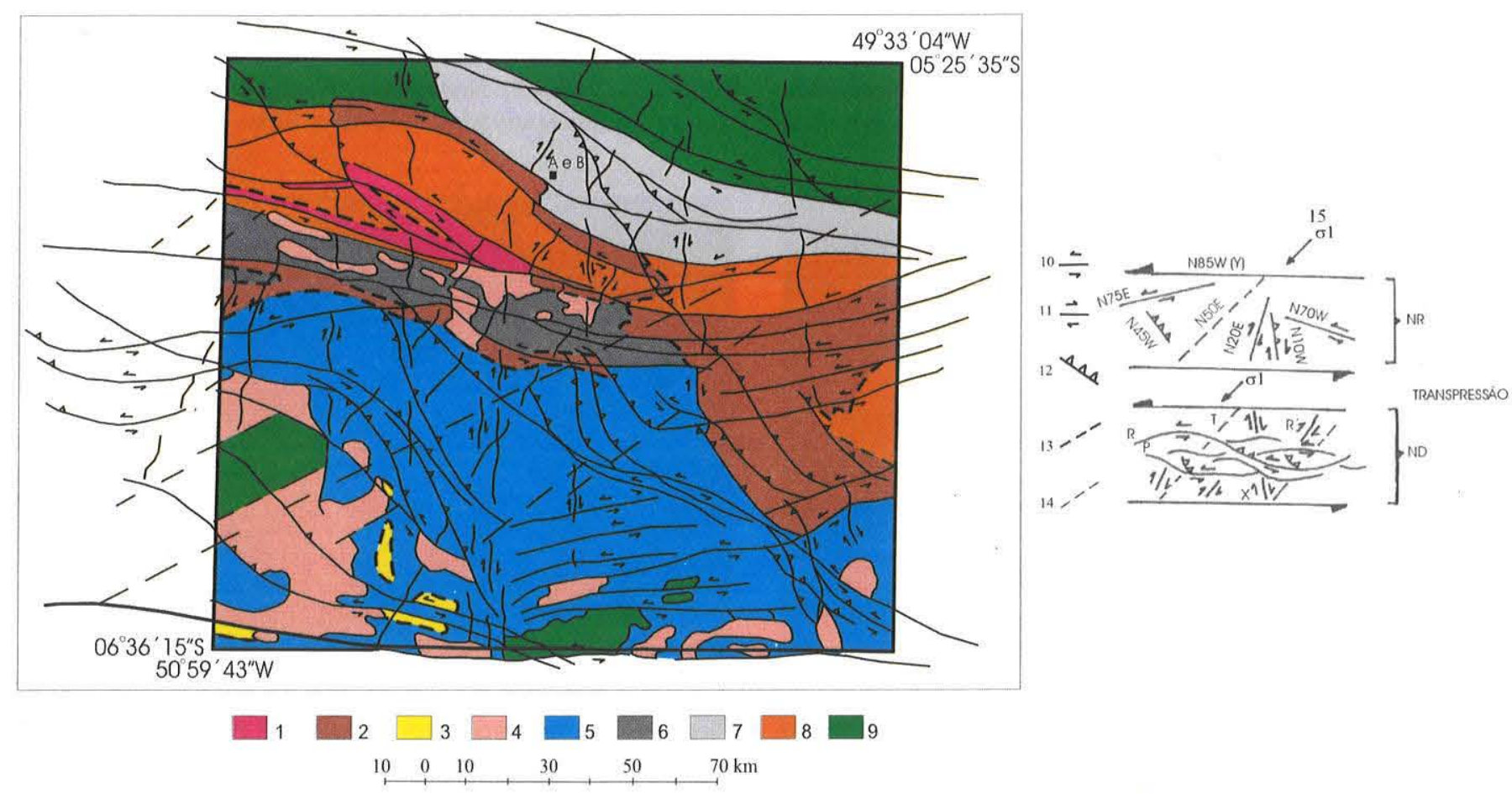

Figura 5 - Esquema da primetra fase de deformação. LEGENDA: Unidades geológicas: I - Grupo Igarapé Pojuca; 2 - Grupo Igarapé Salobo; 3 - Grupo Sapucaia; 4 - Suite Plaquê; Complexo Granítico - Gnáissico ( 5 - Complexo Xingu Indiferenciado; 6 Complexo Xingu A; 7 - Complexo Xingu B; 8-Complexo Xingu C; 9-Complexo Pium e Suite Monte Bacajaí). Estruturas e modelos deformacionais: 10 - ZCT sinistral; 11 - ZCT destral; 12 - ZC inversalempurrão; 13 - ZC rúptil; 14 - contatos geológicos aproximados; 15 - modelo transpressivo sinistral. Localizações: I-área recoberta pela imagem ScanSAR Narrow; II - área comum das imagens TM-Landsat-5 e RADARSAT-I Standard; A e B-localização aproximada, respectivamente, das figuras 6 e 7.

Granítico Estrela e no terminal horse tail da Serra Pelada, indica o desenvolvimento de estruturas transtrativas dos tipos releasing bends, splays divergentes e possivelmente, em níveis crustais superiores, de rhombo chasms. Tais estruturas propiciaram o início do adelgaçamento e são responsáveis pela anomalia crustal na região, favorável ao embaciamento, sedimentação, vulcanismo e granitogênese, representados na atualidade pelas unidades do Grupo Grão-Pará (incluindo o Grupo Rio Novo e o Complexo Luanga), pelo Complexo Granítico Estrela e pelas unidades mais novas, meso a neoproterozóicas (Tabela 2). Considera-se a mega estrutura de Carajás como uma anomalia em comparação com as áreas tanto a Norte como a Sul, bem como a Leste e a Oeste, que aparentemente apresentaram um comportamento mais estável, em relação ao tectonismo de natureza rúptil a rúptil-dúctil que criou condições para o desenvolvimento dos fenômenos mencionados.

SEGUNDA FASE Caracterizou-se por cisalhamento transcorrente, destral-oblíquo ao longo da direção WNW-ESE (Fig. 8), com natureza dúctil a rúptil-dúctil, não coaxial, com vergência de NNW para SSE. Propiciou as condições favoráveis para o alojamento e posterior deformação do Complexo Granítico Estrela (2,70 Ga), bem como deformou suas encaixantes (Supergrupo Itacaiúnas) e as rochas do Complexo Granítico - Gnáissico (Tabela 2).

Importantes aspectos de controles tectônico - estruturais podem ser destacados: 1 - o já citado do alojamento do Complexo Granítico Estrela. Na figura 8 observa-se claramente a geometria de estruturas romboédricas (transtrativas), devido à combinação formada entre as ZCTs orientadas em torno de ENE-WSW e NW-SE (T), na região onde ocorreu a intrusão; 2 - esta geometria, acrescida das direções orientadas em torno de WNW-ESE, também é marcante na região da Serra dos Carajás e justifica o adelgaçamento crustal responsável pelo embaciamento onde, posteriormente, depositaram-se os sedimentos da Formação Águas Claras (Tabela 2) e; 3 -embora existam deformações dúcteis devidas a esta fase, principalmente nas rochas do Complexo Granítico - Gnáissico (Tabela 2), o caráter rúptil a rúptil - dúctil predomina. Um dos exemplos mais marcantes destas deformações é observado em certos afloramentos das rochas máficas e ultramáficas do Grupo Rio Novo e do Complexo Luanga (neste trabalho englobados no Grupo Grão-Pará), na região de Curionóplis, Serra Pelada. A seqüência intrusiva é perfeitamente identificada, isto é, verifica-se a ocorrência desde as ultramáficas (harsburgitos. piroxenitos, etc.) na base até os leucogabros no topo, inclusive com acamamento ígneo(Si) perfeitamente preservado (Suita \& Nilson 1988, Veneziani \& Okida 2001).

As estruturas geradas e/ou deformadas nesta fase ocorrem generalizadamente nas rochas mais antigas, do Complexo Granítico - Gnáissico até as mais novas do Supergrupo Itacaiúnas/Complexo Granítico Estrela (Tabela 2). Como foi citado, apresentam desde uma natureza dúctil até rúptil. Foram escolhidos quatro exemplos, em nível de afloramento, dois na Suíte Plaquê (Figs. 9e 10), um no Complexo Luanga (Fig. 11) e o último em um pequeno lajedo de 
A evolução tectono-estratigráfica da Provincia Mineral de Carajás: um modelo com base em dados de sensores remotos orbitais (SAR-C RADARSAT-1, TM LANDSAT-5), aerogeofisica e dados de campo

granito correlacionável ao Complexo Estrela (Fig. 12).

TERCEIRA FASE Caracterizou-se por movimentos transpressivos (localmente transtensivos), que deram origem a estruturas rúpteis a rúpteis-dúcteis (Fig. 13). Afetou todas as unidades geológicas, desde as arqueanas $(>2,8 \mathrm{Ga})$ até as neoproterozóicas (Grupo Buritirama, Tabela 2). Novamente, as antigas linhas de fraquezas crustais foram reativadas durante o fluxo de massa rochosa

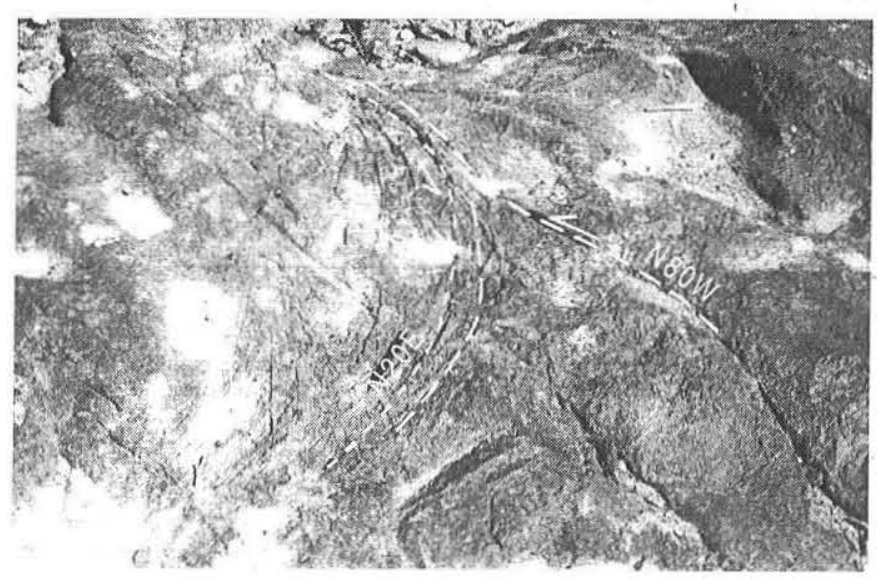

Figura 6-Localização aproximada: A na figura 5. Afloramento do Complexo Xingu B, de gnaisse intercalado tectonicamente com anfibolito. Ambos litotipos apresentam-se intensamente deformados e estirados. Destacam-se bandas de cisalhamento centimétricas definidas ao longo das foliações miloníticas. Observa-se o nítido arrasto dúctil das estruturas orientadas segundoN2OE ver, ao longo da direção N8OW ver: (Fig. 4, Y ou D), com sentido sinistral.

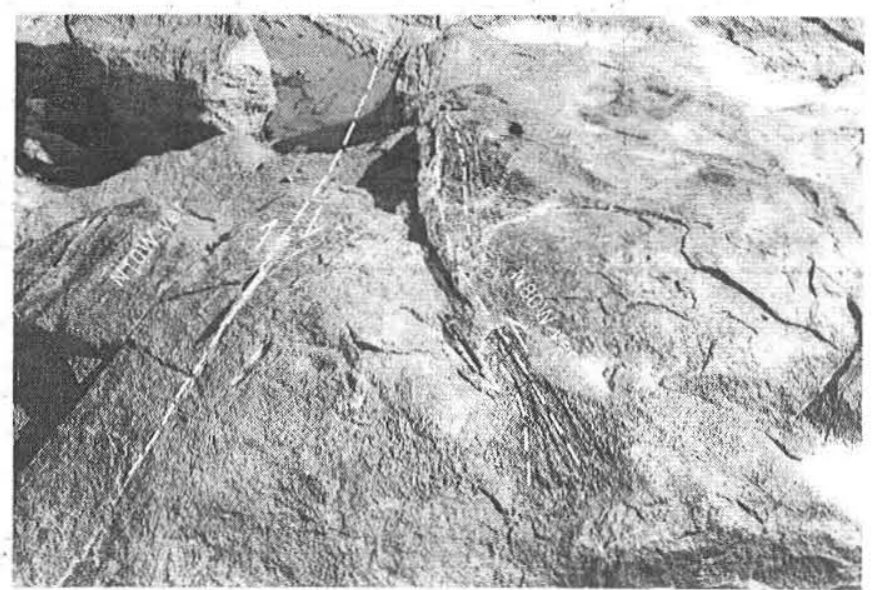

Figura 7 - Localização aproximada: B na figura 5 . Neste caso, observa-se o arrasto dúctil da foliação milonítica orientada segundo N80W ver. ( $Y$ ou D), indicando movimentação com sentido destral, ao longo da ZCT orientada segundo NIOW ver: Esta corresponde a direção de X (Fig. 4).
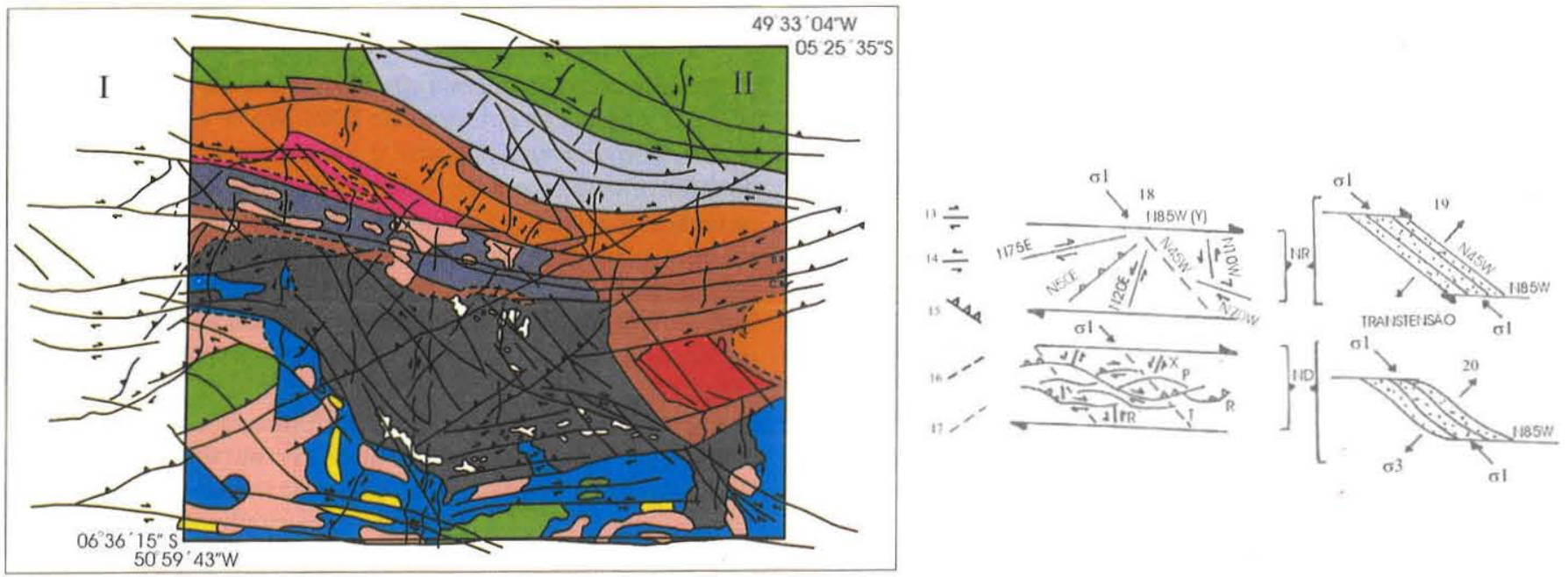

$06^{\circ} 36^{\prime} 15^{\prime \prime} 5^{\prime 2}$

$\square_{1} \square_{2} \square_{3} \square_{4} \square_{5} \square_{6} \square_{7} \square_{8} \square_{9} \square_{10} \square_{11} \square_{12}$

$10 \quad 0 \quad 10,30,50,70 \mathrm{~km}$

Figura 8 - Esquema da segunda fase de deformação. Legenda: Unidades geológicas: Grupo Grão-Pará (I - Formação Carajás; 2 - Formação Parauapebas, incluindo o Complexo Luanga e o Grupo Rio Novo); 3 - Complexo Granítico Estrela; 4 - Grupo Igarapé Pojuca; 5 - Grupo Igarapé Salobo; 6 - Grupo Sapucaia; 7 - Suite Plaquê; Complexo Granítico - Gnáissico ( 8-Complexo Xingu Indiferenciado, 9 - Complexo Xingu A, 10 - Complexo Xingu B, II - Complexo Xingu C, 12 - Complexo Pium e Suite Monte Bacajai). Estruturas e modelos deformacionais: 13 - ZCT destral; 14 - ZCT sinistral; 15 - ZC inversa/empurrão; 16 - ZC rúptil; 17 - contatos geológicos aproximados; 18 - modelo transpressivo destral; 19-releasing bend; 20 - restraining bend. Obs.: NR - nível rúptil; ND-nível dúctil. Localizações: I-área recoberta pela imagem ScanSAR Narrow; II-área comum das imagens TM-Landsat5 e RADARSAT-1 e Standard; A - localização aproximada das figuras 9 e 10 e B e C-, respectivamente, das figuras 11 e 12. 
(vergência) de NE para SW, que provocou movimentação sinistral ao longo da direção principal de cisalhamento (Y ou D) e, ao longo das demais direções estruturais, deslocamentos compatíveis aos do modelo adotado.

O caráter predominantemente rúptil, a estruturação regional devida à combinação das ZCTs orientadas em torno de WNWESE com as falhas trativas originando estruturas romboédricas e, terminação em splays extensivos na região de Serra Pelada, contribuíram para a preservação das características das unidades

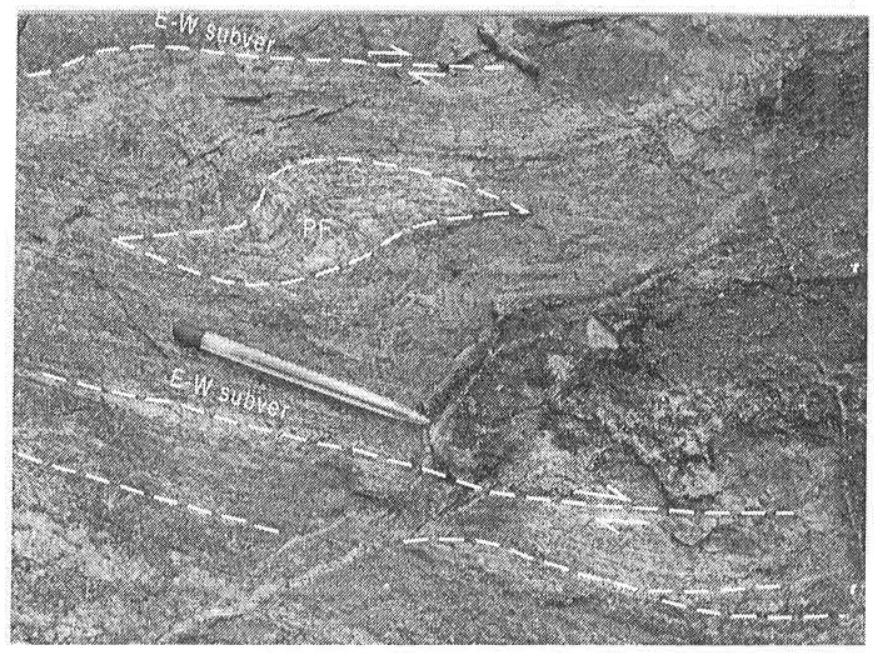

Figura 9-Localização aproximada: A na figura 8. Na região da Cachoeira do Deus-me-livre (Rio Itacaiúnas), em grandes lajedos onde ocorrem intercalações tectônicas de granitos da Suite Plaquê e gnaisses tonalíticos (Tab. 2) verificam-se deformações dúcteis. A foto ilustra um augen de K feldspato, assimétrico, mais resistente ao fluxo milonítico em uma matriz fina, mais dúctil, que indica o sentido destral para o movimento ao longo da direção E-W ver., bem definida pela foliação milonítica.

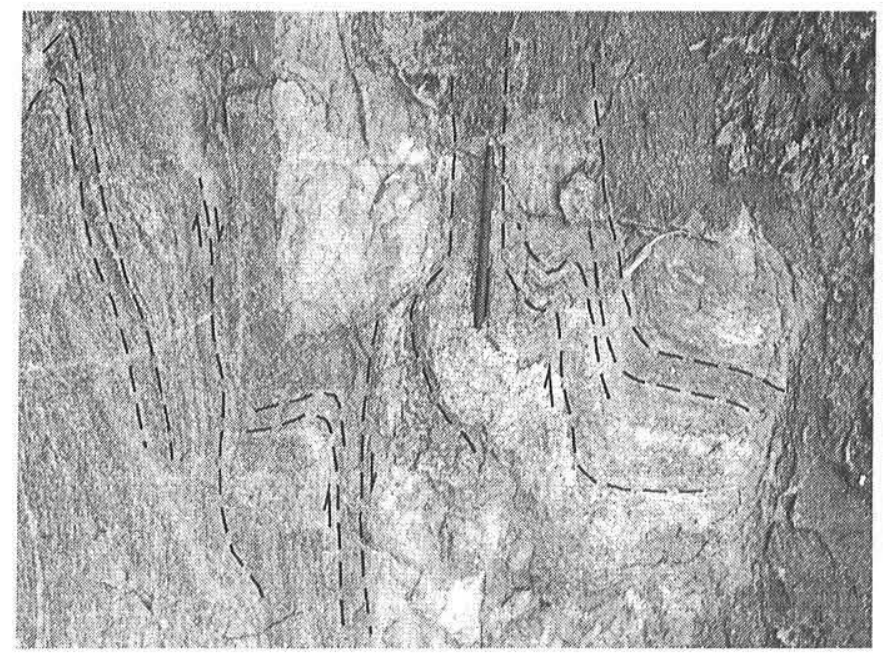

Figura 10-Localização aproximada: A na figura 8. No mesmo afloramento da figura 9 (Suite Plaquê), observam-se dobras da foliação milonítica (St) geradas pela movimentação destral ao longo da direção N85E ver:

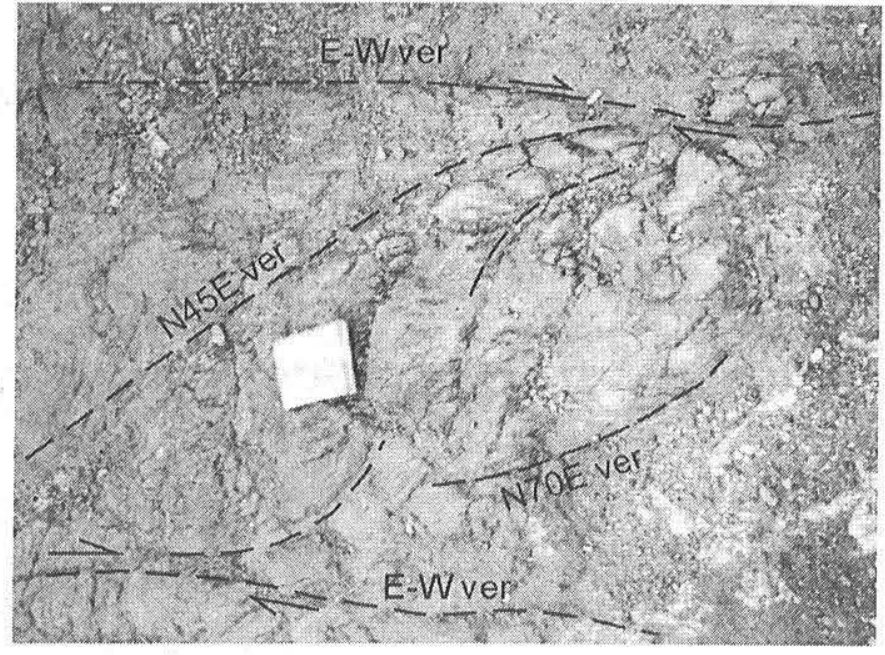

Figura 11 - Localização aproximada: B na figura 8. Neste local ocorrem piroxenitos correlacionáveis ao Complexo Luanga (Tab.2). As rochas encontram-se deformadas por cisalhamento de natureza rúptil - dúctil. Observa-se as foliações cataclástico - miloníticas (série cataclástica coesa) orientadas segundo as direções E-W ver: N70E ver: e N45E ver: $O$ arranjo espacial e o inter-relacionamento destas foliações (arrasto e off-set) indicam movimentação destral ao longo das ZCTs orientadas segundo E-W.
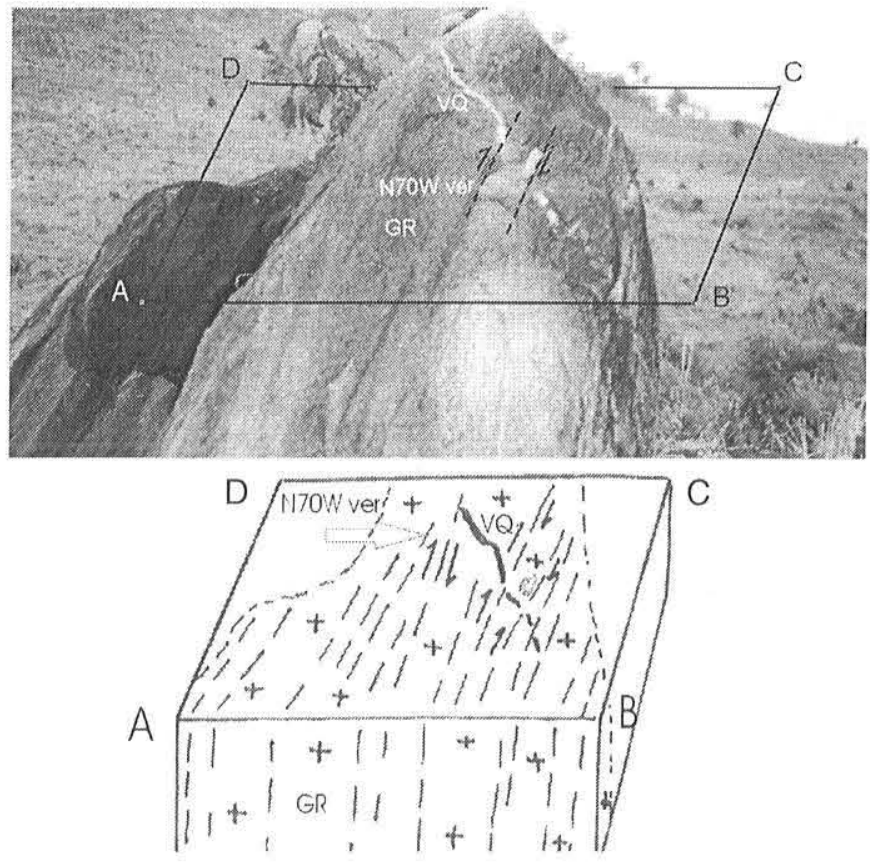

Figura 12 - Localização aproximada: C na figura 8. Afloramento de granito sintectônico do tipo Estrela (Tab. 2), foliado e cortado por veios de quartzo verticalizados. A foliação tem origem rúptil - dúctil (série cataclástica coesa) e orienta-se segundo N7OW ver: Representa a deformação por ZCT com movimentação destral mostrada pela flexura e rompimento do veio de quartzo. O bloco diagrama representa esquematicamente a projeção das estruturas em questão no plano horizontal. 

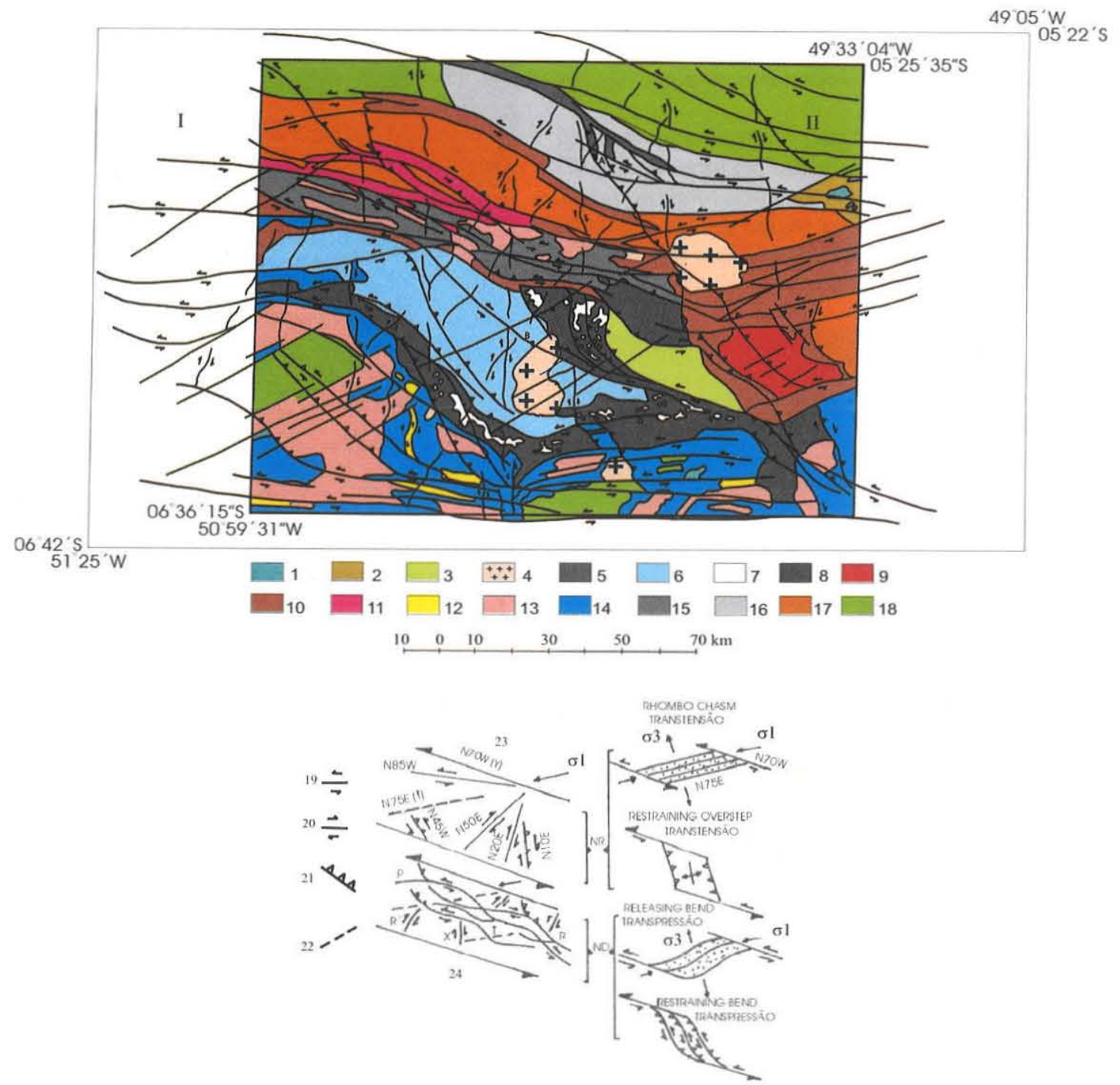

Figura 13 - Esquema da terceira fase de deformação. LEGENDA: Unidades geológicas: I - intrusivas básicas; 2 - Grupo Serra Grande; 3 -Formação Gorotire; 4 - Granitos Anorogênicos; 5 - Grupo Buritirama; 6-Formação Águas Claras; Grupo Grão-Pará (7 - Formação Carajás; 8 - Formação Parauapebas, incluindo o Complexo Luanga e o Grupo Rio Novo); 9 - Complexo Granítico Estrela; 10 - Grupo Pojuca; 11 - Grupo Igarapé Salobo; 12 - Grupo Sapucaia; 13 - Suite Plaquê; Complexo Granítico-Gnáissico (14 - Complexo Xingu Indiferenciado, 15 - Complexo Xingu A, 16 - Complexo Xingu B, 17 - Complexo Xingu C, 18 - Complexo Pium e Suite Monte Bacajaí). Estruturas e modelos deformacionais: 19-ZCT sinistral; 20-ZCT destral; 21 - ZC empurrão/inversa; 22 - ZC rúptil; 23 - modelo transpressivo rúptil sinistral; 24 - modelo transpressivo dúctil sinistral. Obs.: NR - nível rúptil; ND nível dúctil. Localizações: I -área recoberta pela imagem ScanSAR Narrow; II-área comum das imagens TM-Landsat-5 e RADARSATI Standard; A e B-localização aproximada, respectivamente, das figuras 14 e 15.

geológicas dos grupos Grão-Pará (incluindo o Grupo Rio Novo e o Complexo Luanga, Tabela 2), Igarapé Pojuca e Igarapé Salobo, importantes por conterem os principais jazimentos minerais da região ( $\mathrm{Fe}, \mathrm{Au}, \mathrm{Cu}, \mathrm{Pt}, \mathrm{Mn}$, etc.). Alem disso, foram responsáveis pela continuidade do adelgaçamento crustal que controlou o embaciamento/deposição/deformação da Formação Águas Claras, e propiciou as condições favoráveis para o alojamento dos granitos anorogênicos (Tabela 2, 1,88 Ga).

As estruturas geradas e/ou deformadas nesta fase distribuemse de modo amplo e afetam praticamente todas as unidades tectono- estratigráficas da região. Isto é, desde aquelas com idade arqueana até a Formação Gorotire, do Neoproterozóico (Tabela 2). Foram escolhidos dois exemplos em nível de afloramento, respectivamente em quartzitos do Grupo Buritirama e em um dos ramos da Falha de Carajás, na Formação Águas Claras (Figs. 14 e 15).

Eventos evolutivos pós 1,88 Ga. Após a terceira fase de movimentação, Veneziani et al. (2001) verificaram uma acomodação geral das antigas linhas de fraquezas crustais, que gerou um pequeno rejeito destral (centimétrico) ao longo das direções 


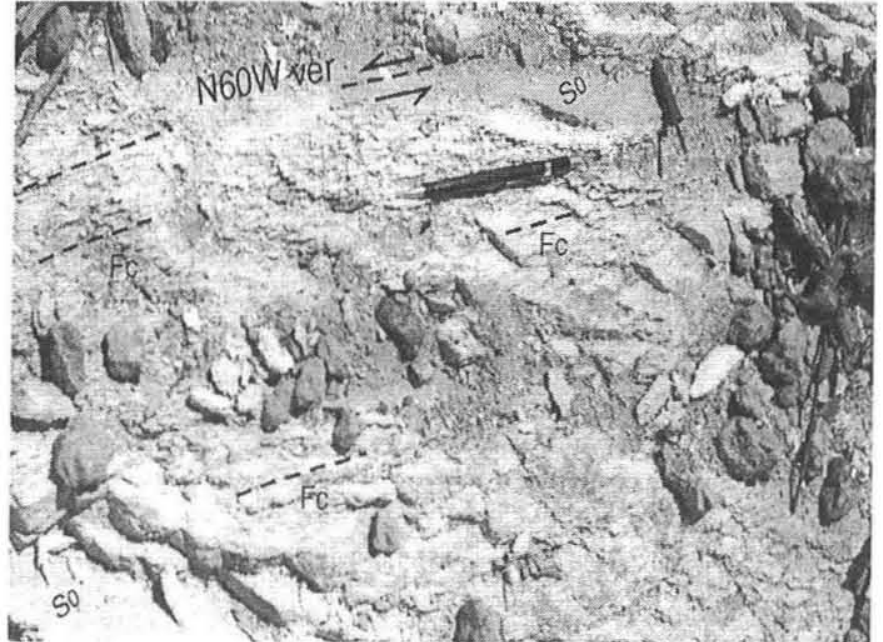

Figura 14 - Localização aproximada: A na figura 13. Afloramento de quartzito micáceo do Grupo Buritirama. Observase a estrutura primária So (acamamento - tampa da caneta) preservada devido ao caráter rúptil desta fase, cortada deformada por ZCT orientada segundo N6OW ver: (lapiseira), responsável pelo desenvolvimento da foliação cataclástica $(f c)$. A orientação de So original na região é NSW 20NE (Fig. I). No local afetado pela ZCT ocorre inflexão para NW-SE devida ao movimento sinistral.

orientadas em torno de E-W. Tal rejeito foi observado inclusive no Granito Cigano (anorogênico), na região do contato deste com as encaixantes.

Do Eoproterozóico em diante, ocorreram apenas movimentos gravitacionais que propiciaram a formação de bacias sedimentares, como a de Serra do Paredão, a intrusão de várias gerações de diques e de sills básicos, preferencialmente controlados pelas antigas linhas de fraquezas crustais. Os principais picos distensivos relacionam-se ao final do Proterozóico/início do Paleozóico, Mesozóico e Terciário.

CONCLUSÕES $\quad 1-\mathrm{A}$ análise integrada das imagens StandardRADARSAT-1 (cenas ascendentes e descendentes), ScanSAR Narrow-RADARSAT-I e TM-Landsat-5, constitui-se numa fonte muito satisfatória na obtenção de dados tectônico - estruturais e litoestratigráficos regionais, pois as diferentes geometrias de observação/iluminação dos produtos utilizados amenizaram, sensivelmente, as perdas de informações inerentes ao uso de imagens que não permitam variações relativas aos azimutes solar/ iluminação e/ou elevação solar/incidência. Além disso, a visão sinóptica da superfície do terreno que torna possível determinar a configuração espacial - geométrica das feições com significado tectônico - estrutural, permitiu a comparação com os modelos deformacionais consagrados na literatura geológica e, desta forma, a seleção prévia de pontos chaves para a verificação em nível de afloramentos;

2 - Os produtos integrados TM-Landsat-5 - gama e StandardRADARSAT-1 - gama, embora não disponíveis para toda a região estudada, combinam as informações morfoestruturais (dados de sensoriamento remoto) com aquelas devidas às diferentes respostas dos litotipos, ou associações destes (gamaespectro-
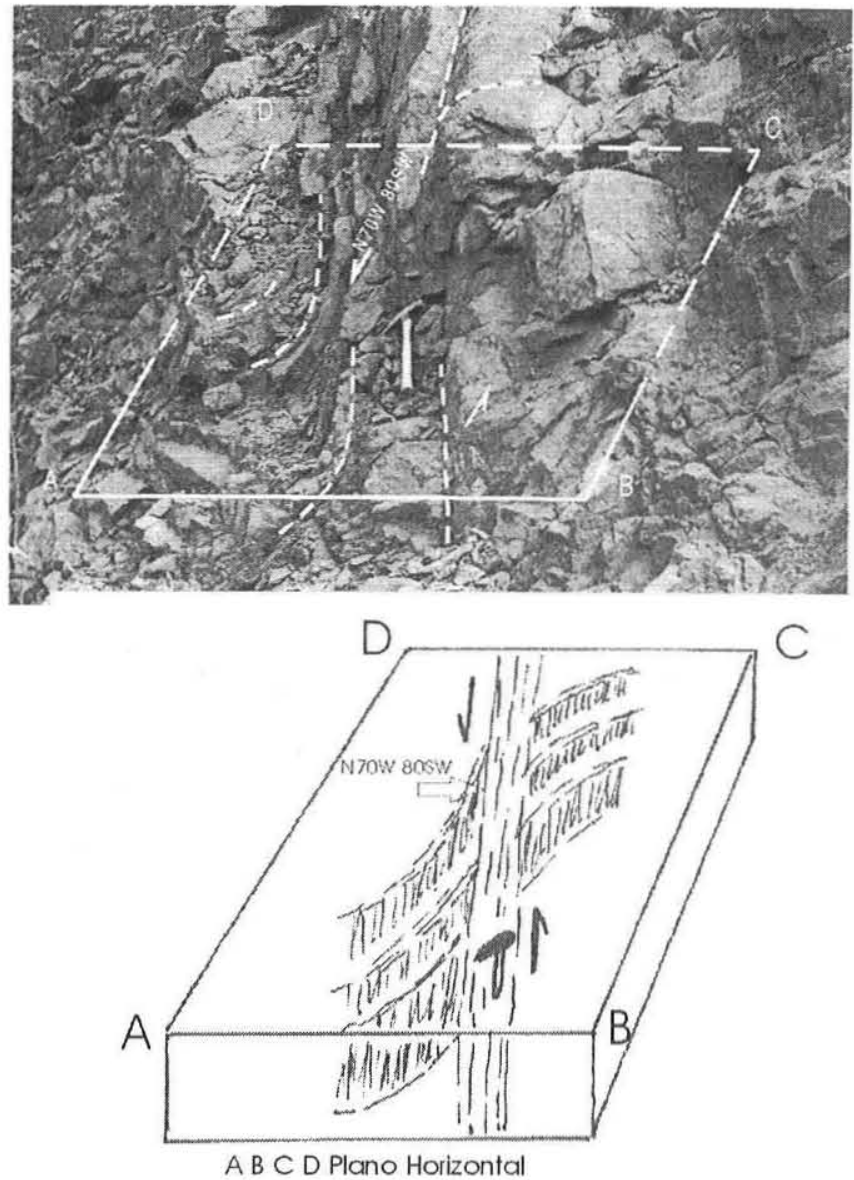

Figura 15 - Localização aproximada: B na figura 13. Afloramento de siltito da Formação Águas Claras. Observa-se a verticalização de So devido ao movimento transcorrente sinistral ao longo da direção N70W 60SW (martelo), que corresponde à ZCT Carajás. $O$ dobramento, a silicificação e o rompimento de So são resultantes transpressivos da terceira fase e característica dos níveis crustais superiores, correspondentes as deformações da série cataclástica incoesa. O bloco diagrama representa esquematicamente a projeção das estruturas em questão no plano horizontal.

metria). Istoé, juntamente com o grau de deformação das unidades tectono-estratigráficas é possível analisar as características inerentes a composição mineralógica destas, em função das respostas radiométricas. Desta forma, a discriminação das unidades tectono-estratigráficas tornou-se muito mais segura, quando comparou-se as regiões com e sem disponibilidade de dados gamaespectrométricos;

3 - A comparação entre os dados morfoestruturais, obtidos com a interpretação dos produtos utilizados, e aqueles dos modelos teórico - empíricos consagrados proporcionou a identificação de feições tectono-estruturais que indicaram a existência das fases de movimentação/deformação ocorridas na região, bem como auxiliaram a compreensão do arcabouço geotectônico regional.

Agradecimentos Os autores agradecem à Canadian Space Agency (CSA) pelas imagens RADARSAT-I do Programa ADRO, 
ao Serviço Geológico do Brasil (CPRM) pelos dados aerogeofísicos, aos colegas Stélio Soares Tavares Júnior e Rosana
Okida pela contribuição na computação gráfica das ilustrações, e às críticas e sugestões dos revisores da RBG.

\section{Referências}

Araújo O.J.B., Maia R.G.N., Jorge João X. da S., Costa J.B.S. 1988. A megaestruturação arqueana da Folha Serra dos Carajás. In: Congr. Latinoamericano de Geol., 1, Belém, Anais, p. 324-338.

Araújo O.J.B., Costa J.B.S., Pinheiro R.V.L., Maia R.G.N.M., Macambira E.M.B., Vale A.G., Siqueira J.B., Jorge João X. da S. 1992. Arcabouço estrutural do complexo de bacias transcorrentes arqueanas da região de Serra dos Carajás. In: SBG, Congr. Bras. Geol., 37, São Paulo, Resumos Expandidos, v. 1, p. 547-548.

Araújo O.J.B., Maia R.G.N. 1991. Serra dos Carajás, Folha SB-22-Z-A. Relatório Final. CPRM, Rio de Janeiro, 136p.

Barros C.E. de M. \& Dall'Agnol R. 1994. Deformação de rochas granitóides em regime dúctil: o exemplo do Gnaisse Estrela, região de Carajás. Revi. Bras. Geoc., 23:315-332.

Biddle, K.T. \& Christie-Blick, N. (eds.) 1985. Strike-slip deformation, basin formation, and sedimentation. Tulsa. Soc. Econ. Paleont. Min., p. 1-32 (Publ. Sp. n. 37).

Cordani U.G. \& Brito Neves B.B. 1982. The geological evolution of South America during the Archean and Early Proterozoic. Revi. Bras. Geoc., 12:78-88.

Costa J.B.S., Araújo O.J.B., Jorge João X.S., Maia R.G.N.M., Macambira E.M.B., Lafon J.M., Vale A.G., Santos A., Pena Filho J.I.C., Neves A.P. 1994. Panorama tectono-estrutural da região sudeste do Estado do Pará. In: SBG, Simp. Geol. Amazônia, 4, Belém, Resumos Expandidos, p. 314-317.

Costa J.B.S., Araújo O.J.B., Santos A., Jorge João X.S., Macambira M.J.B., Lafon J.M. 1995. A Província Mineral de Carajás: aspectos tectono - estruturais, estratigráficos e geocronológicos. Bol.do Museu Paraense Emílio Goeldi (Série Ciências da Terra), 7:199-235.

DOCEGEO 1988. Revisão litoestrátigráfica da Província Mineral de Carajás. In: SBG, Congr. Bras. Geol., 25, Belém, Anexo, 10-54.

Figueiras A.J.M., Macambira J.B., Villas R.N.N. 1987. Contribuição ao estudo paleoambiental da Formação Rio Fresco na região de Carajás - PA. In: Simp. sobre Sistemas Deposicionais no Pré-Cambriano, Ouro Preto, Anais, p. 17-30.

Harding T.P. 1974. Petroleum traps associated with wrench faults. AAPG Bull., 7:1290-1304.

Hasui Y. \& Haraly N.L.E. 1985. Integração de informações geofísicas e geológicas na definição de estruturas crustais brasileiras. Revi. Bras, Geof., 4:248-249.

Hirata W.K., Rigon J.C., Kadekaru, K., Cordeiro A.A.C., Meireles E. de M. 1982. Geologia da Província Mineral de Carajás. In: SBG, Simp. Geol. Amazônia, 1., Belém, Anais, p. 100-108.

Lab K.L. \& Costa J.B.S. 1992. Evolução litoestrutural do Duplex Serra Pelada. In: SBG, Cong. Bras. de Geol., 37. Bol. de Resumos Expandidos, São Paulo, 1, 350-351.

Macambira E.M.B., Vale A.G., Jorge João X.S., Costa J.B.S. 1994. O quadro geológico da Folha São Félix do Xingu (SB.22-Y-B). In: SBG, Congr: Bras. Geol., 38, Balneário de Camboriú, Anais, p. 111112.

Meireles E.M., Hirata W.K., Amaral A.F., Medeiros Filho C.A., Gato W.C. 1984. Geologia das Folhas Carajás e Rio Verde, Província Mineral de Carajás, Estado do Pará. In: SBG, Congr. Bras. Geol.. 34, Rio de Janeiro, Anais, 5:2163-2174.
Oliveira J.R. de, Silva Neto C.S., Costa E.J. de S. 1994. Serra Pelada, Folha SB.22-X-C. Relatório Final. CPRM, Brasília, 220p.

Paradella W.R., Bignelli P.A., Veneziani P., Pietsch R.W., Toutin T. 1997. Airborne and spaceborne Synthetic Aperture Radar (SAR) integration with Landsat TM and Gamma Ray Spectrometry for geological mapping in a tropical rainforest environment, the Carajás Mineral Province, Brazil. Intern. J. Rem. Sensing, 18:1483-1501.

Paradella W.R., Santos A.R., Dall'Agnol R., Pietsch R.W., Sant'Anna M.V. 1998. A geological investigation based on airborne (SAREX) and spaceborne (RADARSAT-1) SAR integrated products in the Central Serra dos Carajás Granite area, Brazil. Can. Jour. Rem Sensing, 24:376-392.

Pinheiro R.V.L. 1997. Reactivation history of the Carajás and Cinzento Strike Slip Systems, Amazon, Brazil. University of Durham, UK, Ph.D Dissertation, 408p.

Pinheiro R.V.L. \& Holdsworth R.E. 2000. Evolução tectonoestratigráfica dos sistemas transcorrentes Carajás e Cinzento, Cinturão Itacaiúnas, na borda leste do Craton Amazônico, Pará. Revi. Bras. Geoc., 30:597606.

Santos A.R., Paradella W.R., Veneziani P., Liu C.C., Sant'Anna M.V. 1997. Integração de dados SAR-TM e SAR-GAMA em estudos geológicos na Província Mineral de Carajás (Brasil). In: SELPER, Simp. Latinoamericano de Percepcion Remota, 8, Mérida, Venezuela, CD-ROM.

Santos A.R., Veneziani P., Paradella W.R., Morais M.C. 2001. Radar Aplicado ao Mapeamento Geológico e Prospeç̧ão Mineral: Aplicações. São José dos Campos, INPE, 103p. (INPE-8117-PUD/ $45)$.

Siqueira J.B. \& Costa J.B.S. 1991. O Duplex Salobo - Mirim, Serra dos Carajás. In: SBG, SNET, 3, Rio Claro, Boletim, p. 47-48.

Suita M.T.F. \& Nilson A.A. 1988. Geologia do Complexo MáficoUltramáfico Luanga (Província de Carajás, Pará) e das unidades encaixantes. In: SBG, Congr, Bras. Geol., 35, Belém, Anais, v. 6, p. 2813-2826.

Teixeira W., Tassinari C.C.G., Cordani U.G., Kawashita K. 1989. A review of the geochronology of the Amazonian Craton: tectonic implications. Prec. Res., 42:213-217.

Veneziani P. 1987. Análise de movimentos da tectônica rúptil e rúptil dúctil através da interpretação de produtos de sensores remotos na região do Espinhaço Meridional (MG): uma correlação com processos evolutivos. Inst. de Geociências, Universidade de São Paulo. São Paulo. Tese de Doutoramento, 186p.

Veneziani P. \& Okida R. 2001. Mapeamento geológico-estrutural da região do Projeto Platina (Serra Pelada) baseado em dados integrados RADARSAT-TM-aerogeofísica. Relatório Técnico. Companhia Vale do Rio Doce, 52p.

Veneziani P., Santos A.R., Paradella W.R., Morais M.C. 2001. Fases de Movimentação Tectônica ao longo do Cinturão de Cisalhamento Itacaiúnas, Carajás, PA. In: SBG, Simp. Geol. Amazônia, 7, Belém, PA, CD-ROM.

Manuscrito A-1385

Recebido em 20 de outubro de 2002

Revisão dos autores em 30 de novembro de 2003 Revisão aceita em 10 de dezembro de 2003 